\title{
¿Cómo PeNSAR EL AFECTO EN LA POLÍTICA? \\ APROXIMACIONES Y DEBATES EN TORNO A LA \\ TeOría de la Hegemonía de ERNESTo LAClaU
}

\author{
How to Think Affect in Politics? Approaching the Theory of Hegemony \\ of Ernesto Laclau.
}

\begin{abstract}
ANA BELÉN BLANCO
\end{abstract}
Universidad de Buenos Aires

\author{
MARÍA SOLEDAD SÁNCHEZ \\ Universidad de Buenos Aires
}

\begin{abstract}
RESUMEN
Este artículo se propone aprehender la forma en la que la dimensión del afecto es problematizada en la teoría de la hegemonía de Laclau, a partir de una reconstrucción de sus principales conceptos teóricos así como de los debates intelectuales que se han suscitado al respecto. Presentaremos un recorrido transversal por las producciones del autor a fin de reconstruir sucintamente los elementos fundamentales que componen su teoría. Posteriormente, profundizaremos sobre la incorporación de la dimensión afectiva como un componente primario de todo proceso de construcción hegemónica, explicitando la imposibilidad de reducir esta última a operaciones estrictamente lingüísticas. Abordar el vínculo entre hegemonía y economía afectiva permite revalorizar el aporte teórico de Laclau al identificar las herramientas heurísticas que este brinda para el análisis sociopolítico.
\end{abstract}

Palabras clave: Hegemonía, afecto, Laclau, política, discurso.

\begin{abstract}
In this article we discuss the affective dimension in Laclau's theory of hegemony. We offer a reconstruction of Laclau's theory and focus on the incorporation of the affective dimension as an inherent component of every process of hegemony construction. We argue that this affective component cannot be strictly reduced to linguistic operations. By considering the relation between hegemony and affective economy we can revalue the theoretical contribution of Laclau, identifying the heuristic tools he offered for socio-political analysis.
\end{abstract}

Key words: Hegemony, affection, Laclau, politics, discourse. 


\section{INTRODUCCIÓN}

La teoría de la hegemonía desarrollada por Ernesto Laclau representa un aporte innovador y sistemático para la articulación de un pensamiento político en una época donde los conceptos clásicos de la teoría política han perdido solidez explicativa frente a las transformaciones de las sociedades contemporáneas, entre las que podemos destacar las nuevas formas de organización de un "capitalismo flexible", la emergencia y proliferación de luchas políticas y sociales que resultan inaprehensibles bajo el tradicional concepto de clase, la puesta en cuestión del Estado Nación y el fin de las ideologías totalizadoras características del mundo polar de la Guerra Fría (Critchley y Marchart, 2008). Si bien la obra de Laclau ha sido revisitada y problematizada extensamente por diversos analistas (Alemán, 2009; Biglieri y Perelló, 2012; Elliott, 1995; Critchley y Marchart, 2008; Stavrakakis, 2010), al mismo tiempo que se ha ofrecido como marco teórico para la reflexión sobre procesos políticos específicos (Biglieri y Perelló, 2007; Hall, 1998, Stavrakakis, 2010), entendemos que la potencialidad de ciertas dimensiones analíticas de la misma no ha sido aún suficientemente explorada. En este sentido, identificamos que la reflexión en torno a la categoría del afecto constituye uno de estos núcleos que merece ser atendido con mayor detalle. Y esto porque consideramos que la dimensión del afecto es central, no solo para el abordaje de la teoría laclausiana, sino para la construcción de un pensamiento político que no se reduzca a una perspectiva meramente institucional o puramente racional.

El presente artículo se propone problematizar la forma en que Laclau incorpora la dimensión del afecto a su teoría de la hegemonía, buscando reconstruir tanto las categorías conceptuales que el autor desarrolla como los debates que actualmente se despliegan en torno a su tratamiento de la temática. Los desarrollos tardíos de este pensador contemporáneo se orientan a explicitar, por una creciente incorporación de categorías lacanianas (como lo Real, el goce, el objeto a, entre otras), la imposibilidad de reducir la teoría de la hegemonía a las operaciones lingüísticas (en el sentido restringido del término). En otras palabras, Laclau persigue destacar el carácter indisociable de la dimensión afectiva en todo proceso de construcción política de una totalidad social. En términos del autor:

"Toda sobredeterminación requiere no solo condensaciones metafóricas sino también investimientos catécticos. Es decir, que algo que pertenece al orden del afecto tiene un rol primario en la construcción discursiva de lo social. Freud ya lo sabía: el vínculo social es un vínculo libidinal. Y el afecto no es algo agregado a la significación sino consustancial a ella" (Laclau, 2008: 402).

Así, si bien la obra de Laclau puede ubicarse en un campo heterogéneo de estudios englobados bajo la denominación de "teorías del discurso", podría ser pensada como una disrupción de ese campo por su elección del psicoanálisis, y de la teoría lacaniana en particular, como la única perspectiva capaz de aprehender en forma simultánea los elementos semióticos y libidinales de toda construcción discursiva de lo social. 
“De modo que si considero que la retórica es ontológicamente primaria en explicar las operaciones inherentes a la construcción hegemónica de la sociedad y las formas que esta adopta, considero que el psicoanálisis es el único camino válido para detectar las pulsiones que operan detrás de esa construcción" (Laclau, 2008: 402).

La referencia a la teoría lacaniana para el análisis político crítico no constituye una característica exclusiva de la teoría de la hegemonía de Laclau; antes bien, es posible identificar una constelación de autores que actualmente recibe la denominación de "izquierda lacaniana" (Stavrakakis, 2010) y que, aún con especificidades, reconocen esta articulación como punto de partida teórico. En la trayectoria intelectual de Laclau, como se ha dicho, puede reconocerse una creciente disposición a la incorporación de categorías lacanianas fundamentales. Aunque muchas de ellas están presentes desde sus primeros escritos vinculados a la construcción de la teoría de la hegemonía -especialmente en Hegemonía y Estrategia Socialista. Hacia una radicalización de la democracia (Laclau y Mouffe, 2010)-, fue posteriormente que el autor ha sistematizado sus esfuerzos por especificar la afinidad inmediata con el psicoanálisis lacaniano.

Para evidenciar estos desplazamientos presentaremos un recorrido transversal por los textos de Laclau, con el objetivo de profundizar en la caracterización de la articulación entre política y afecto en su teoría. Entendemos que una reflexión que permita aproximarnos a la reconstrucción de la forma en la que, a lo largo de la obra laclausiana se presenta dicha articulación, puede aportar claridad sobre uno de los puntos centrales en torno al que se organiza una parte importante de los actuales debates en el campo del posmarxismo (que buscaremos también reseñar, especialmente el fructífero intercambio con Glynos y Stavrakakis). Asimismo, consideramos que tal reconstrucción permite identificar las herramientas heurísticas que esta perspectiva brinda al análisis político y social, al considerar que todo proceso de identificación supone necesariamente apegos ideológicos pero también afectivos.

\section{UNA ONTOLOGÍA DES-FUNDAMENTADA}

La articulación primaria entre la obra de Laclau y el psicoanálisis se funda, en términos de Alemán (2009), en la vocación ontológica de Lacan. Problematizando la tradición filosófica que ha presentado la ontología como una teoría acerca del "modo en que la realidad se configura, aquello que la fundamenta y sostiene, el sentido que emana de este fundamento y el sujeto que es capaz de ser el soporte de dichas operaciones" (Alemán, 2009: 13), Alemán sostiene que el proyecto ontológico lacaniano implica la construcción de un discurso acerca de lo que la realidad es, pero sin buscar un fundamento último que la explique.

La teoría lacaniana comparte con los enfoques postestructuralistas la crítica del sujeto clásico, es decir, de un sujeto entendido como racional, indiviso, autotransparente y estable. Sin embargo, su especificidad radica en que, conjugando una noción de deseo como negatividad y una reformulación de los desarrollos estructuralistas sobre el 
lenguaje, ${ }^{1}$ Lacan postula al sujeto como sujeto del deseo y sujeto del lenguaje (Lacan, 2005a; 2005b). De forma sucinta, el proceso de adquisición del lenguaje cumpliría en reducir la multiplicidad del cuerpo mediante su inscripción en un orden socio-simbólico, que no es otra cosa que un sistema de diferencias. El sujeto en su singularidad se origina, entonces, a partir de su inserción en la cadena significante (Rifflet-Lemaire, 1981). El ingreso al orden simbólico que hace posible al sujeto como tal presupone, al mismo tiempo, una pérdida irrecuperable: el sacrificio de todo acceso inmediato a lo Real, un resto inasimilable que resiste a la simbolización y que permanece por lo tanto excluido del orden sociosimbólico (Tonkonoff, 2009). El sujeto lacaniano es un sujeto barrado en tanto está atravesado y constituido por la falta de lo Real. El sujeto es "falta en ser" (Lacan, 2000); nunca es una sustancia, sino que es aquello que emerge de su propia fractura, de su propia imposibilidad. En este sentido, Zizek afirma que "el sujeto no es sino la imposibilidad de su propia representación significante", y más adelante, "el sujeto es estrictamente correlativo a su propia imposibilidad; su límite es su condición positiva" (Zizek, 1998: 266). De este modo, Lacan abre las puertas a una teoría de la ontología quebrada que coloca en el centro una fractura que no puede ser reparada ni suturada. Es así que en el fundamento ontológico hay un hiato que no puede ser cerrado nunca, pero que no por eso va a dejar de tener efectos. Este lugar ontológico que impide la plenitud del ser pasa a ocupar el lugar de la causa del ser y de su movimiento. El fundamento ausente se transforma en causa de los imposibles pero necesarios intentos por llenar ese vacío (Alemán, 2009). Sin embargo, la falta lacaniana no solo atraviesa al sujeto sino también al Gran Otro, el orden cultural (Elliott, 1995; Zizek, 1998). Laclau desarrollará su teoría de la hegemonía partiendo de esta ontología de la falta, que supone la imposibilidad de pensar cualquier identidad (subjetiva o social) como una unidad cerrada, estable, definitiva.

En relación con el nivel subjetivo, es imprescindible destacar, como uno de los desplazamientos mencionados en relación con la incorporación de las categorías lacanianas, que la noción del sujeto-como-falta es incorporada por Laclau en Nuevas reflexiones sobre la revolución de nuestro tiempo (1993), al abandonar el concepto estructuralista de "posición de sujeto" presente en Hegemonía y Estrategia Socialista. Hacia una radicalización de la democracia (Laclau y Mouffe, 2010). Determinante fue, en este punto, el debate entablado con Slavoj Zizek, a fines de los ochenta y condensado en El sublime objeto de la ideología (Zizek, [1989] 1998), acerca del estatuto del sujeto lacaniano, sujeto que no puede nunca quedar reducido a una posición en el discurso, ya que el sujeto se encuentra barrado por una falta identitaria constitutiva e insuperable.

"Esto le permitió evitar estancarse en una idea de la subjetividad completamente pasiva (...). En consecuencia, la identidad ya no se concibe como un mero efecto de construcción estructural, sino que es el resultado de los procesos de identificación 
desatados por esa 'falta de identidad' originaria llamada 'el sujeto'" (Critchley y Marchart, 2008: 22).

En relación con el nivel social, Laclau sostiene que no existe un espacio suturado al que podamos denominar "sociedad". A partir de esta ontología de la des-fundamentación, el movimiento creativo llevado a cabo por este autor tiene que ver con colocar en el lugar del fundamento (ausente) a la contingencia y, por lo tanto, a la política como intento siempre fallido de construcción de una totalidad que es imposible pero necesaria al mismo tiempo. Imposible porque lo social está constitutivamente abierto: no hay ningún principio subyacente, ningún sujeto trascendental ni ninguna teleología que ocupe el lugar del fundamento. El fundamento de lo social es un lugar vacío. Necesario, ya que sin un cierre, por más precario que este sea, no sería posible ninguna significación ni identidad (Laclau, 2007). Si esto es así, ya no puede pensarse en un sujeto o en identidades plenas a priori, porque estas no existen más allá de su construcción en el campo de lo político. Si el fundamento es un vacío imposible de llenar, toda respuesta efectiva a esta imposibilidad será una suspensión transitoria de la misma. La contingencia, entonces, es la categoría que invariablemente articula el juego de lo necesario/imposible. La relación que constituye al campo de lo político es "la negociación entre dos inconmensurables" (Alemán, 2009: 99).

\section{HACIA UNA TEORÍA DE LA HEGEMONÍA}

Partiendo de las premisas de que no existe positividad de lo social y de que la política se funda en esta relación entre lo imposible y lo necesario, Laclau propone la categoría de hegemonía como la operación en donde la construcción de una sutura se vuelve posible. En términos del autor, "las prácticas hegemónicas son suturantes en la medida en que su campo de acción está determinado por la apertura de lo social, por el carácter finalmente no-fijo de todo significante" (Laclau y Mouffe, 2010: 77). En otras palabras, si el campo de la discursividad -aquel exceso de sentido inherente a toda situación discursiva- es el terreno necesario de constitución de toda práctica social, la operación hegemónica se define como una práctica articulatoria que hace posible una fijación (provisoria) de ese campo de flotancia, limitando la productividad de la cadena significante y posibilitando el establecimiento de identidades que se definan por sus posiciones diferenciales en el sistema. La categoría de discurso en este esquema refiere precisamente a esa totalidad estructurada que resulta de la práctica articulatoria (Laclau y Mouffe, 2010).

Laclau recupera la categoría de hegemonía desarrollada por Antonio Gramsci, aunque proponiendo su reconstrucción teórica a partir del concepto de práctica articulatoria. La especificidad de esta práctica articulatoria hegemónica es que no parte del presupuesto de una totalidad estructural u orgánica previa, donde las identidades de los elementos y sus relaciones están ya establecidas. Por el contrario, Laclau rechaza la concepción de la sociedad como totalidad fundante de sus procesos parciales, afirmando que la estructura discursiva (el orden de las relaciones sociales) es siempre el resultado de esta práctica articulatoria. 
Debemos destacar, por otra parte, que Laclau renuncia a la idea de un sujeto político constituido a priori, ya sea definido en términos de clase $\mathrm{u}$ otras categorías esencializantes. ${ }^{2}$ Si lo político es primario y constitutivo de lo social, ninguna clase o actor social puede poseer un privilegio ontológico. La articulación hegemónica no responde a la lógica específica de una fuerza social única: "el problema del poder no puede plantearse en términos de la clase o del sector dominante que constituye el centro de una formación hegemónica" (Laclau y Mouffe, 2010: 180). Mas, si no hay un sujeto de la hegemonía constituido a priori, ¿cómo es posible una operación hegemónica en los términos de Laclau? Si el fundamento de lo social es un lugar vacío, ¿qué forma adopta su representación? Si bien la falta es constitutiva de toda realidad sociopolítica, esto no significa que los intentos de positivación de cierta plenitud se diluyan. Por el contrario, son estos intentos de rellenar ese vacío los que instituyen la articulación hegemónica como operación política. "Aunque la plenitud y la universalidad de la sociedad son inalcanzables, no desaparecen: se mostrarán siempre a través de la presencia de su ausencia" (Laclau, 1996: 53). Aquí es donde la categoría de significante vacío emerge en el esquema conceptual de este autor, para referir justamente al significante de esa ausencia. Sin embargo, sería imposible aprehender la especificidad de dicha categoría sin referirnos antes a los conceptos de límite y exterioridad.

\section{LÍMITE Y EXTERIORIDAD}

Establecimos que esta perspectiva renuncia a la idea de un espacio suturado y de una representatividad plena, a causa de su imposibilidad ontológica. Pero, asimismo, afirmamos que sin la producción de un cierre que interrumpa el flujo de las diferencias propio del campo de la discursividad, ninguna identidad, ni subjetiva ni social, sería posible. Todo sistema necesariamente implica, entonces, el trazado de un límite. Más allá del límite, hay una exclusión: una exterioridad que será constitutiva del propio sistema. Exterior/ Interior son categorías que se requieren mutuamente. ${ }^{3}$ Paradójicamente, "aquello que constituye la condición de posibilidad de un sistema significante-sus límites- es también aquello que constituye su condición de imposibilidad -el bloqueo de la expansión continua del proceso de significación-" (Laclau, 1996: 71). La cuestión del límite y la exterioridad será objeto de una serie de reformulaciones a lo largo de la trayectoria intelectual de Laclau, que dan cuenta de una complejización en la comprensión de esta problemática teórica y evidencian la progresiva referencia a las categorías lacanianas para pensar la política. Fundamentalmente, la inclusión de los conceptos de dislocación y heterogeneidad muestran la preocupación del autor por profundizar la integración de la dimensión de lo Real lacaniano en sus análisis.

2 Es esta cuestión lo que diferencia fundamentalmente la definición de la hegemonía de Gramsci y la de Laclau: "Según argüimos en el texto, el pensamiento de Gramsci es solo un momento transicional en el paradigma político esencialista del marxismo clásico. Porque para Gramsci, el núcleo de toda articulación hegemónica continúa siendo una clase social fundamental" (Laclau y Mouffe, 2010: 22).

3 El concepto de extimidad desarrollado por Lacan refiere a esta condición íntima de lo exterior, lo que complejiza la relación entre lo simbólico y lo Real. Ver Lacan, 1991. 
En Hegemonía y estrategia socialista. Hacia una radicalización de la democracia, el límite es pensado en términos de antagonismo. El antagonismo es aquí presentado como la experiencia del límite de lo social (más específicamente, de la objetividad de lo social): atestigua la imposibilidad de la sociedad de constituirse plenamente, a la vez que habilita la conformación de una equivalencia entre las diferencias del sistema respecto del elemento excluido. Podemos afirmar que un límite antagónico refiere a la instauración de una exclusión fundante y no simplemente de una diferencia más, ya que si lo que se establece es una diferencia, esta sería continua con las diferencias existentes al interior del sistema.

"Esto implica que una formación solo logra significarse a sí misma -es decir, constituirse como tal- transformando los límites en fronteras, constituyendo una cadena de equivalencias que construye a lo que está más allá de los límites, como aquello que ella no es. Es solo a través de la negatividad, de la división y del antagonismo, que una formación puede constituirse como horizonte totalizante" (Laclau y Mouffe, 2010: 188).

Sin embargo, si en un primer momento identificaba el límite del discurso con el concepto de antagonismo, a partir de Nuevas reflexiones sobre la revolución de nuestro tiempo, e incorporando nuevamente las críticas realizadas por Slavoj Zizek (1998), Laclau complejizará el análisis introduciendo el concepto de dislocación y, posteriormente, el de heterogeneidad. Estas categorías le permitirán avanzar en la problematización de un exterior constitutivo no reductible a la noción de antagonismo, porque esta presupondría ya una articulación discursiva. El antagonismo dejará ahora de resultar un equivalente de la exclusión radical y comenzará a referir a una forma particular de dominio de esa fractura ontológica: una dicotomización del espacio social, donde "ambos lados de la relación antagónica son necesarios para crear un espacio único de representación" (Laclau, 2008: 394). El antagonismo es una forma de inscripción discursiva de algo más primario en relación con los límites de un sistema significante que Laclau llamará dislocación y que referirá a la imposibilidad de lo simbólico de hacer con lo Real. La categoría de dislocación da cuenta

"del hecho de que lo social, o la sociedad en tanto totalidad presupuesta, está siempre ya 'dislocado' por un exterior que, sin embargo, no siempre ni necesariamente debe ser construido discursivamente en la forma del antagonismo" (Critchley y Marchart, 2008: 22).

Posteriormente, en La razón populista, Laclau sumará el concepto de heterogeneidad para el análisis de los límites del sistema. El tipo de exterioridad al que hace referencia con este concepto se vincula a la exterioridad del espacio de representación como tal (y no solo a la exterioridad a aquello que dentro de un espacio de representación es asociado a la noción de antagonismo). La heterogeneidad permite reflexionar sobre lo Real, no solo como falta en lo simbólico, sino como un exceso no dialectizable (Laclau, 2007; Biglieri y Perelló, 2012). Es decir, que siempre habrá un residuo que no puede ser incorporado a la cadena significante, un resto que no es nunca una exterioridad pura sino que insiste siempre en la propia lógica de la constitución interna (Laclau, 2007). 
Cabe señalar que la articulación de las categorías de antagonismo, dislocación y heterogeneidad permanece abierta a futuras reflexiones.

"Tal como veo las cosas al presente, los límites de una formación discursiva no son homogéneos sino que se constituyen mediante la articulación inestable de las tres dimensiones descriptas [dislocación, antagonismo, heterogeneidad] y el pasaje de una hacia la otra" (Laclau, 2008: 394).

\section{SIGNIFICANTES VACÍOS: EL JUEGO DE LO PARTICULAR Y LO UNIVERSAL}

La práctica hegemónica permite la construcción de una totalidad social a partir de la articulación de elementos heterogéneos. De allí que la hegemonía "se ha convertido en el nombre de la lógica general de la institución política de lo social" (Critchley y Marchart, 2008:18). Esta articulación supone la fijación de una cadena discursiva a partir de la institución de un punto nodal, que aglutina las diferencias en una cadena equivalencial. Avanzando en la especificidad del punto nodal para la teoría de la hegemonía, Laclau propone el concepto de significante vacío para dar cuenta de aquel significante que, precisamente, tiene la característica de renunciar a su identidad diferencial para así representar la identidad equivalencial de un espacio social en un momento político dado. "Este vaciamiento de un significante de aquello que lo liga a un significado diferencial y particular es, según vimos, lo que hace posible la emergencia de significantes "vacíos" como significantes de una falta, de una totalidad ausente" (Laclau, 1996: 78). Por esto, los significantes vacíos refieren a aquellos puntos que, dentro del sistema de significación, no expresan ningún contenido positivo, sino que tienen por función nominar una plenitud ontológicamente imposible. Su vacuidad no puede homologarse a un "significante sin significado", debido a que "es un vacío que puede ser significado porque es un vacío dentro de la significación" (Laclau, 2007: 136). Cualquier término que sea producido como el significante de la falta en un determinado contexto político pasa a ser un significante vacío. Sin embargo, no todo significante tiene las mismas posibilidades de encarnar en un momento dado la función universal. Laclau hace referencia al carácter "desnivelado" de lo social para dar cuenta de que existen localizaciones desiguales, resultado de procesos en los que la lógica de la equivalencia y la diferencia se sobredeterminan entre sí: "No toda posición en la sociedad, no toda lucha es igualmente capaz de transformar sus contenidos en un punto nodal que pueda tornarse un significante vacío" (Laclau, 1996: 81). La lucha hegemónica es precisamente la lucha por llenar ese vacío, por medio de la presentación de un contenido parcial como la representación de esa totalidad que lo desborda.

Recién en este punto se vuelve evidente la definición formal que Laclau esboza de la hegemonía: la operación hegemónica se define como una articulación entre lo particular y lo universal, donde una cierta particularidad óntica asume el lugar ontológico de una universalidad imposible. En la ontología social presentada por Laclau el todo va a ser siempre -necesariamente- encarnado por una parte: esta no es un elemento de una totalidad preexistente sino "una parte que es el todo" (Laclau, 2007: 146). Cuando un 
contenido parcial logra efectivamente presentarse como el significante de esa plenitud ausente podemos decir que ha logrado hegemonizar la cadena equivalencial. ${ }^{4}$ Se ha instituido como punto nodal de dicha formación discursiva, es decir, ha logrado fijar (al menos temporalmente) el flujo de las diferencias, unificando el campo y haciendo posible la identidad. La función de fijación nodal tiene entonces un efecto performativo sobre la identidad/unidad de los objetos que son, de este modo, resultado de la propia operación de nominación. ${ }^{5}$ El enfoque lacaniano permite comprender que la identidad y la unidad del objeto son resultado del efecto retroactivo del nombrar. Es el punto nodal el que produce la unidad de la formación discursiva definiendo retroactivamente la identidad de los elementos.

\section{EL AFECTO EN LA TEORÍA DE LA HEGEMONÍA: LAS CUESTIONES EN DEBATE}

Ahora bien, ¿pueden los procesos de identificación políticos ser vistos solo como resultados de procesos de nominación, en sentido estricto? $\mathrm{O}$, para decirlo de otro modo, ¿puede el proceso de fijación de un punto nodal reducirse a su capacidad para efectuar una clausura en términos simbólicos? ¿Es la hegemonía solo una operación lingüística? Para abordar estas interrogantes es necesario profundizar en la forma en la que Laclau incorpora la categoría de lo Real lacaniano en su análisis. Es decir, reflexionar sobre la presencia y la caracterización que, dentro de la teoría de la hegemonía, encuentran los elementos irreductibles al orden del significante.

La noción de lo Real ha sido tematizada por Lacan especialmente en su obra tardía, presentando un nivel cada vez mayor de complejización. Paulatinamente, Lacan irá definiendo lo Real no solo en términos negativos -en tanto límite alienante de la significación-, sino que también lo ligará a la jouissance (o goce) como su modalidad positiva. Esto es, la falta lacaniana no quedará reducida al límite del discurso, sino que la falta es también una falta de jouissance desde el punto de vista de la dialéctica del deseo. La falta en el Otro no es solo una falta de recursos simbólicos, sino la falta de un goce (presimbólico), aquella plenitud que sacrificamos para ingresar al orden sociosimbólico y que se presenta siempre como algo perdido. El concepto lacaniano de jouissance referirá a aquello que, para decirlo con Freud, se encuentra "más allá del principio del placer".

$4 \quad$ El análisis de la identidad popular que Laclau despliega en La razón populista da cuenta de cómo se establece esta relación entre universalidad y particularidad: “la demanda que cristaliza la identidad popular está internamente dividida: por un lado es una demanda particular, por el otro, su propia particularidad comienza a significar algo muy diferente de sí misma: la cadena total de demandas equivalenciales. Aunque continúa siendo una demanda particular, pasa a ser también el significante de una universalidad más amplia que aquella" (Laclau, 2007: 124).

5 La reflexión en torno a la relación entre las palabras y las cosas ha sido uno de los problemas centrales de la filosofía del siglo XX, dando lugar a la aparición de dos grandes corrientes analíticas: el descriptivismo y el antidescriptivismo. Mientras que el descriptivismo plantea una relación fija entre el significante y el significado, el antidescriptivismo supone la autonomización del significante respecto del significado. Los autores posmarxistas, con el fundamental aporte de Zizek, reconocen el importante avance de los antidescriptivistas, aunque señalan que la separación entre la nominación y la descripción no ha conducido a un incremento de la complejidad de las operaciones de nominación (Laclau, 2007). 
Un goce paradójico que no puede representarse con plenitud en el sentido; que no está hecho de sentido, pero que, no obstante, inviste al sentido (Stavrakakis, 2010). ${ }^{6} \mathrm{~A}$ pesar de su incorporación tardía, la jouissance ocupa un lugar central dentro del corpus teórico lacaniano. No se trata de un mero complemento o una hipótesis ad hoc de la que pudiera prescindirse, sino que constituye un elemento fundamental de su edificio conceptual (Miller, 2005). Esta categoría presenta una extensa (y encriptada) tipología que excede con mucho los fines del presente análisis ${ }^{7}$. Nos circunscribiremos solo a dos modalidades de la jouissance, aquellas que han sido recuperadas para el análisis político: el fantasma (la jouissance bajo el género del placer) y el síntoma (la jouissance bajo el género del displacer) (Miller, 2005). Diversas reflexiones contemporáneas han mostrado la productividad de dichas categorías para el estudio de procesos sociales y políticos, como se evidencia en la "lectura sintomática" que propone Slavoj Zizek (1999; 2004; 2004b) y en los análisis centrados en la dimensión fantasmática de los procesos identitarios, como los de Stavrakakis (2010). Estos analistas, entre otros, han señalado que excluir del marco teórico lacaniano la problemática del goce implica una reducción de su potencialidad heurística, en tanto es esta noción la que permite comprender la instauración, la dinámica y la permanencia de identificaciones tanto subjetivas como sociopolíticas. Desde esta perspectiva, la teoría lacaniana no solo proporciona herramientas para el análisis de los efectos simbólicos e imaginarios de la identificación política, sino que también pone de relieve el modo en que estas representaciones simbólicas e imaginarias se encuentran investidas por la energía (fantasmática y/o sintomática) de la jouissance (Stravakakis, 2010). Esto equivale a decir que ciertos puntos nodales se afianzan porque además de proporcionar una cristalización simbólica hegemónica, operan eficazmente sobre la dimensión afectiva. Es por esto que un análisis de tipo discursivo deconstructivo aparece como condición necesaria aunque no suficiente para comprender el apego a ciertos objetos particulares de la identificación. "El capitonnage ideológico efectuado mediante un punto nodal semiótico tiene que sostenerse mediante su anudamiento en el nivel afectivo de la jouissance para afianzarse" (Stravakakis, 2010: 42). Y es precisamente este anudamiento afectivo el que explica su fijación a lo largo del tiempo, así como las dificultades que generalmente encuentra todo proceso de transformación sociopolítico.

La forma en la que la cuestión del afecto es incorporada en los análisis de Ernesto Laclau es objeto, actualmente, de un considerable debate intelectual en el que se intenta elucidar la apropiación del herramental analítico lacaniano (particularmente de la dimensión de lo Real) en la teoría de la hegemonía. A partir de La razón populista, y en sus textos posteriores, Laclau ha abordado con mayor especificidad y claridad la centralidad que, dentro de su teoría, adquiere la dimensión del afecto, presentándola explícitamente como constitutiva en todo proceso de fijación nodal. Este gradual despliegue argumentativo ha estado motorizado fundamentalmente, aunque no exclusivamente, por la serie de

Aquella distinción fundamental de la teoría freudiana entre representación y afecto es resignificada por Lacan como diferenciación entre significante y jouissance (Fink, 2004).

Para profundizar en la tipología lacaniana de la jouissance, ver: Braunstein (2003); Evans (1998); Miller (2003); Nasio (1993). 
críticas que autores como Jason Glynos y Yannis Stavrakakis, entre otros, han presentado a la teoría de la hegemonía en relación con la necesaria incorporación del rol de la jouissance, para ellos ausente en los primeros desarrollos del intelectual argentino. Estos intercambios han permitido -como en otro momento ocurrió con las críticas realizadas por Zizek en torno a las nociones de sujeto y de antagonismo- afinar y precisar las categorías y relaciones que conforman el corpus conceptual laclausiano.

Es indudable que la teoría de la hegemonía desarrollada por Laclau capta de forma temprana y novedosa todo el impacto de la presencia de lo Real lacaniano en tanto límite del discurso. Desde sus primeros trabajos, ha referido a la categoría de lo Real para dar cuenta de la falta constitutiva del orden simbólico, aquella "imposibilidad de la sociedad", que es tanto límite como condición de posibilidad del necesario juego de identificación política. El interés que el autor presenta por abordar esta dimensión negativa de lo Real aparece explicitado en el desarrollo y reformulación de los conceptos de antagonismo y dislocación, que ya han sido revisitados. Ellos dan cuenta de la incapacidad del orden simbólico de alcanzar una significación plena, así como de la vocación del autor por complejizar la caracterización de los límites del espacio de representación. Sin embargo, lo Real no solo es aprehendido en su dimensión negativa, sino que esta imposibilidad fundamental presenta, para Laclau, una dimensión intrínsecamente productiva: es la falta en lo simbólico la que posibilita la lógica de la construcción hegemónica. Siguiendo de cerca a Lacan, afirma que, aunque la clausura es inalcanzable por definición, su imaginarización como totalidad es siempre necesaria. Incorporando nuevos elementos de lo Real lacaniano que no lo reduzcan a su presencia dislocadora, Laclau sostiene que los límites de la significación se positivan en lo que denomina significantes vacíos. Su caracterización de los significantes vacíos evidencia una afinidad teórica inmediata con las positivaciones de lo real por medio del objet petit a de Lacan (Stavrakakis, 2010: 96) y, por lo tanto, con la energía fantasmática de la jouissance.

Para Lacan, la falta de lo Real se imaginariza por la producción del fantasma y su ofrecimiento de un objet petit a. El objeto-causa del deseo (u objet petit a) refiere a un objeto parcial que asume la representación de la Cosa freudiana, es decir, de aquella plenitud inalcanzable. El objeto a plasma en un doble movimiento la falta en el Otro y la promesa de su satisfacción, al presentarnos un objeto milagroso como la vía de recuperación de la jouissance. El deseo está estructurado, para Lacan, en torno a la interminable búsqueda de la jouissance perdida/imposible, en torno a la promesa de hallarla. La denominación del objeto a como objeto-causa del deseo da cuenta del proceso en donde el deseo (que carece de objeto fijo, en tanto que el deseo es siempre deseo de lo que falta) se transpone metonímicamente de objeto a objeto. En términos de Zizek, el objeto a encarna "simultáneamente la pura falta, el vacío en torno al cual gira el deseo y que, como tal, causa el deseo y es simultáneamente el elemento imaginario que oculta este vacío, que lo vuelve invisible al llenarlo" (Zizek, 2004: 266). De este modo, se presenta como un rellenado de ese vacío constitutivo. El hecho de que el todo sea, siempre, encarnado por una parte, no es una contingencia de una situación particular, sino una característica estructural de la significación, que convierte al objeto a en uno de 
los elementos centrales de la ontología social lacaniana y que la teoría política laclausiana incorpora como premisa fundamental:

“El conjunto de mi análisis político discursivo se estructura siempre a través de un proceso recíproco, por el que la dimensión de vacío debilita el particularismo de un significante concreto pero, a su vez, esa particularidad reacciona brindando a la universalidad un cuerpo que la encarne" (Laclau, 2011: 15).

Siguiendo la lectura de Lacan que presenta Copjec, Laclau afirma que el objeto parcial no representa a la Cosa, sino que es el propio objeto parcial el que asume su lugar. Dicho objeto parcial es, él mismo, el nombre de la totalidad (Laclau, 2007; 2011). Debido a que no hay acceso directo a la Cosa como tal, los objetos a no son meras representaciones distorsionadas, sino que dichos objetos parciales, investidos afectivamente, encarnan la imposible totalidad. Traduciendo esta formulación psicoanalítica al lenguaje político, Laclau señalará que la hegemonía "no es otra cosa que la investidura, en un objeto parcial, de una plenitud que siempre nos va a evadir porque es puramente mítica" (Laclau, 2007: 148). Es por esto que los significantes vacíos son importantes para la política: si la dislocación es una característica irreductible de la realidad sociopolítica, la producción hegemónica de significantes vacíos, en tanto significantes de la falta, representa el esfuerzo permanente y necesario de rellenado de esa falta constitutiva. En este sentido es que habíamos afirmado que hegemonizar no es otra cosa que llenar el vacío. "La política es posible porque la imposibilidad constitutiva de la sociedad solo puede representarse mediante la producción de significantes vacíos" (Laclau, 1996: 84). Es por esto que "la lógica del objeto a y la lógica hegemónica no son solo similares: son simplemente idénticas" (Laclau, 2007: 149). Se trata de dos formas de nombrar la misma operación, el mismo proceso, en donde una particularidad se vacía de contenido y pasa a ser el nombre de una universalidad inconmensurable ${ }^{8}$. Si bien no hay, para Laclau, ningún contenido óntico predestinado a cumplir la función de representación de la totalidad, esto no debe llevarnos a pensar que se trate de un objeto intercambiable a voluntad de las fuerzas sociales. En virtud de que lo que el objeto encarna es una plenitud inalcanzable, que carece de contenido positivo, el proceso por el que una determinada particularidad adquiere una centralidad inesperada, convirtiéndose en el nombre de algo que la excede, está necesariamente atravesado por la dimensión afectiva. En términos psicoanalíticos, un objeto parcial se convierte en el objeto pleno de investidura catéctica. En términos políticos, una demanda se convierte en el objeto de una investidura radical. Para explicar el cómo y el porqué de tal proceso,

8 La relación hegemónica presenta los mismos momentos estructurales que presentara Lacan en relación con el pequeño objeto a: una cierta particularidad encarna una totalidad que resulta inalcanzable. Se trata de un modelo teórico que se opone a aquel que postula la reificación/ la distorsión/ la falsa conciencia (Laclau, 2011). Mientras que en este último se presupone la posibilidad de un acceso a lo pleno mediante una reversión del proceso de reificación, el modelo de la lógica hegemónica parte de la premisa de que lo pleno resulta inalcanzable, porque, como ya se ha dicho al comienzo de este escrito, carece de todo fundamento. De allí que en lugar de pensar la encarnación en lo concreto como una reificación distorsionante o un ocultamiento, una perspectiva centrada en la articulación hegemónica considera que el investimiento radical de un objeto parcial constituye la única forma de alcanzar una cierta plenitud (aunque siempre precaria e inestable) (Laclau, 2011). 
no basta con analizar las operaciones de significación sino que es necesario referir a una dimensión cualitativamente diferenciada: el afecto. “El afecto (es decir, el goce) constituye la esencia misma de la investidura, mientras que su carácter contingente da cuenta del componente 'radical' de la fórmula" (Laclau, 2007: 148). Podemos afirmar que, además de las operaciones lingüísticas descritas con anterioridad en este artículo, todo significante hegemónico supone una carga afectiva. Esta identidad entre la lógica del objeto a lacaniana y la lógica de los significantes hegemónicos laclausianos ha sido reivindicada por autores de orientación lacaniana como Stavrakakis, en tanto es allí donde Laclau incorpora la modalidad fantasmática de la jouissance. Sin embargo, es este mismo autor el que, simultáneamente, ha señalado la reticencia de Laclau a incorporar otras formas de positivación de lo Real lacaniano que no se reduzcan al proceso de imaginarización (como el síntoma).

De lo dicho hasta aquí se desprende que para Laclau toda formación hegemónica (o discursiva) no solo articula la lógica de la equivalencia y de la diferencia, sino que necesariamente implica una ligazón emocional. La categoría de discurso propuesta por Laclau refiere a este momento relacional constitutivo entre lo lingüístico y lo afectivo. "Los complejos que denomino "discursivos" incluyen dimensiones tanto afectivas como lingüísticas y, ergo, no pueden ser afectivos ni lingüísticos" (Laclau, 2008: 375). Para el autor, entonces, lo discursivo no puede ser reducido a su aspecto lingüístico en sentido estricto, sino que el goce es un elemento consustancial de la significación. Es decir, que no es posible establecer una dicotomía entre las dimensiones de la significación y del afecto. En lugar de presentar un dualismo analítico, Laclau buscará especificar este abordaje relacional de la significación y el afecto a partir de referir a la forma y fuerza de todo discurso (Laclau, 2007; 2008). Laclau señala que si lo social es sinónimo de producción discursiva y, a su vez, lo discursivo se estructura necesariamente a partir de movimientos retóricos, entonces, la retórica es siempre inherente a la gramática y a la lógica social. Ahora bien, si la retórica es la que permite comprender la forma que adquiere la construcción hegemónica -la sobredeterminación o condensación metafórica que posibilita la operación significante- ella no logra aprehender la fuerza que la explica como tal y da cuenta de su permanencia. Toda construcción hegemónica (toda operación discursiva) requiere no solo de condensaciones metafóricas, sino también de investimentos catécticos (Laclau, 2007; 2008). Este doble movimiento estructural por el que una parcialidad logra encarnar la plenitud mítica, supone referir a la presencia de lo Real dentro de lo simbólico; es decir, a la existencia de catexias diferenciadas que invisten a los objetos parciales. El afecto implica un desnivel constitutivo en tanto discontinuidad radical entre un objeto y otro, discontinuidad que solo puede ser entendida en términos de una catexia diferencial (Laclau, 2007).

Estas premisas teóricas se materializan en el estudio del populismo que propone Laclau (2007). Echando por tierra la posibilidad de un análisis estrictamente racional de lo político, el autor señala que el populismo, en tanto la lógica tout court de la política, sería imposible sin una investidura afectiva en un objeto parcial. Y esto porque para el autor la lógica populista refiere a la institución de una plebs (demanda particular) encarnando un populus (el nombre de la totalidad imposible). Cierta demanda particular 
se convierte en el objeto pleno de investidura afectiva, el punto nodal que encarna aquella plenitud imposible. ${ }^{9}$

Si bien es en La razón populista donde Laclau desarrolla en profundidad estas premisas conceptuales, señala que:

"Sería erróneo pensar que, al agregar el afecto a lo que hemos dicho hasta ahora acerca de la significación, estamos uniendo dos tipos diferentes de fenómenos que, al menos analíticamente, serían separables. La relación entre significación y afecto es, de hecho, mucho más íntima que eso" (Laclau, 2007: 142).

Sin embargo, autores como Glynos y Stavrakakis no solo cuestionaron la ausencia de la noción de afecto en sus primeros desarrollos (señalando la imposibilidad de que esta reconceptualización tardía funcione retroactivamente sobre los mismos), sino que también han objetado su incorporación bajo la categoría de discurso, poniendo en discusión la productividad de esta última por omnipresente.

"Ver el discurso y el significante como elementos que todo lo abarcan, considerar coextensos el afecto y la representación, negar que aquí hay dos lados que se hallan en juego, dificulta mucho la tarea de teorizar productivamente la interrelación entre ellos. Por ejemplo, ¿cómo sería posible, en tal marco teórico, establecer una diferencia entre los discursos que logran funcionar con éxito como objetos de investimiento y aquellos que no consiguen interactuar bien con la jouissance (que no logran ser hegemónicos?" (Stavrakakis, 2010: 122).

La problemática del anudamiento de un punto nodal semiótico al nivel afectivo del goce nos enfrenta con la complejidad de todo proceso político: tanto de la posibilidad de una construcción hegemónica como de la del cambio político y social. Continuar profundizando estos debates se presenta como una tarea imprescindible para la teoría política actual, en tanto la reflexión sobre el afecto permite abordar de forma renovada tanto procesos políticos y sociales actuales (la crisis europea actual, la emergencia de gobiernos populares en América Latina, el consumismo, el narcotráfico, los fanatismos religiosos, entre otros) como procesos políticos y sociales que signaron la historia del siglo XX (los fascismos europeos, las dictaduras del cono sur o el stalinismo soviético), evitando la reducción que todo análisis meramente institucional o puramente racional de la política suponen.

9 Para que tenga lugar una articulación populista tiene que darse una relación equivalencial (en relación con el elemento excluido) entre una heterogeneidad de demandas sociales que se articulen en la figura del pueblo. “Una demanda popular, como hemos visto, es la que encarna la plenitud ausente de la comunidad mediante una cadena de equivalencias potencialmente interminable. Es por esto que la razón populista -que equivale, como hemos visto, a la razón política tout court-rompe con dos formas de racionalidad que anuncian el fin de la política: tanto con un evento revolucionario total que, al provocar la reconciliación plena de la sociedad consigo misma volvería superfluo el momento político, como con una mera práctica gradualista que reduzca la política a la administración (...) Una vez que se ha alcanzado esta inversión de la relación parte/todo -una inversión que, como hemos visto, es inherente al objeto a lacaniano y a la relación hegemónica-, la relación populus/plebs se convierte en el lugar de una tensión inerradicable (...) Esta tensión sine die es lo que asegura el carácter político de la sociedad" (Laclau, 2007: 279). 


\section{CONCLUSIÓN}

Hace más de una década que el psicoanálisis, y en particular la teoría lacaniana, ha pasado a ser una referencia central para la reorientación de la teoría política contemporánea (Alemán, 2009; Elliott, 1995; Stavrakakis, 2010). Aunque no se deriva, en forma directa, de la obra de Lacan una teoría política, su pensamiento se caracteriza por un antiutopismo radical que ha sido revisitado por un grupo de autores contemporáneos, sumamente heterogéneos. Los desarrollos de estos últimos comparten la preocupación por establecer un vínculo, hasta entonces inexistente, entre el análisis político crítico y las enseñanzas de Lacan, afirmando las potencialidades que las categorías psicoanalíticas poseen para la construcción de una teoría política que se muestre capaz de aprehender la realidad política y social contemporánea, revalorizando el "momento de lo político" pero remarcando siempre el fondo indecidible sobre el que este viene a inscribirse.

Partir de la premisa de que todo vínculo social es un vínculo libidinal conlleva un replanteamiento de todas las categorías tradicionales del campo de las ciencias sociales, así como una reevaluación de la forma de definir y problematizar las identidades subjetivas y colectivas (Tonkonoff, 2009). El deseo ya no será una categoría residual dentro de los análisis sociopolíticos, sino un eje fundamental para reflexionar sobre la construcción de las identidades. Estas teorías permiten no solo recuperar el énfasis en el carácter discursivo de la construcción de las identificaciones políticas, sino que también, al incorporar la dimensión del afecto al análisis, logran explicar la forma en la que estas identificaciones se invisten de una energía libidinal. Es decir, que toda cristalización simbólica hegemónica supone una carga afectiva que permite comprender tanto su producción y fijación a largo plazo como las dificultades de su desplazamiento y las resistencias al cambio.

Consideramos que la obra de Laclau presenta una particular relevancia en la configuración de este campo de estudios, ya que logra sistematizar una teoría política novedosa y de alto valor heurístico, informada por diversas tradiciones de la filosofía política contemporánea y por el psicoanálisis lacaniano. En este artículo nos hemos propuesto sistematizar algunas de las categorías centrales de la producción de este autor, en pos de reflexionar sobre la relevancia que el anudamiento afectivo posee en toda construcción política. Si bien su teoría de la hegemonía tiene actualmente una amplia recepción, entendemos que esta suele reducirse a su dimensión estrictamente simbólica, soslayando su íntima vinculación con la economía afectiva. De allí que este trabajo haya buscado explorar esta relación, a partir de una reconstrucción de sus categorías analíticas y de los debates intelectuales que se han suscitado al respecto en los últimos años. Laclau ha buscado explicitar la relación (inescindible) entre política y afecto en sus trabajos tardíos, señalando la imposibilidad de reducir la lógica de la hegemonía a un proceso de condensación metafórica (estrictamente lingüístico). Explorar la identidad existente entre la lógica hegemónica y la lógica del objet petit a de Lacan, le ha permitido especificar la centralidad que el investimiento afectivo posee en toda construcción discursiva de una totalidad social. 


\section{REFERENCIAS}

Alemán, Jorge. 2009. Para una izquierda lacaniana... Intervenciones y textos. Buenos Aires: Grama Ediciones. Biglieri, Paula y Perelló, Gloria (eds.). 2007. En el nombre del pueblo: la emergencia del populismo kirchnerista. Buenos Aires: UNSAM Edita.

Biglieri, Paula y Perelló, Gloria. 2012. Los usos del Psicoanálisis en la Teoría de la Hegemonía de Ernesto Laclau. Buenos Aires: Grama Ediciones.

Braunstein, Néstor. 2003. "Desire and jouissance in the teachings of Lacan". En The Cambridge Companion to Lacan, editado por Jean-Michel Rabaté, 102-115. Cambridge: Cambridge University Press.

Critchley, Simone y Oliver Marchart (comps.). 2008. Laclau: aproximaciones críticas a su obra. Buenos Aires: Fondo de Cultura Económica.

Elliott, Anthony. 1995. Teoría Social y Psicoanálisis en transición. Sujeto y Sociedad de Freud a Kristeva. Buenos Aires: Amorrortu Editores.

Evans, Dylan. 1998. "From Kantian Ethics to mystical Experience: An exploration of jouissance". En Key Concepts of Lacanian Psychoanalysis, editado por Dany Nobus, 1-28. Londres: Rebus.

Fink, Bruce. 2004. Lacan to the letter. Minneapolis: University of Minnesota Press.

Glynos, Jason y Stavrakakis, Yannis. 2008. "Encuentros del tipo real. Indagando los límites de la adopción de Lacan por parte de Laclau". En Laclau: aproximaciones críticas a su obra, compilado por Critchley, Simone y Marchart, Oliver, 249-267. Buenos Aires: Fondo de Cultura Económica.

Hall, Stuart. 1998. "Significación, representación, ideología: Althusser y los debates posestructuralistas". En Estudios culturales y comunicación: Análisis, producción y consumo cultural de las políticas de identidad y el posmodernismo, compilado por Curran, et al., 193-220. Barcelona: Paidós.

Lacan, Jacques. 1991. El seminario. Libro 7. Buenos Aires: Paidós.

Lacan, Jacques. 2000. El seminario. Libro 8. Buenos Aires: Paidós.

Lacan, Jacques. 2005a. Escritos 1. Buenos Aires: Siglo XXI.

Lacan, Jacques. 2005b. Escritos 2. Buenos Aires: Siglo XXI.

Laclau, Ernesto. 1993. Nuevas reflexiones sobre la revolución de nuestro tiempo. Buenos Aires: Nueva Visión. Laclau, Ernesto. 1996. Emancipación y Diferencia. Buenos Aires: Ariel.

Laclau, Ernesto. 2007. La razón populista. Buenos Aires: Fondo de Cultura Económica.

Laclau, Ernesto. 2008. "Atisbando el futuro". En Laclau: aproximaciones críticas a su obra, compilado por Critchley, Simone y Marchart, Oliver, 347-404. Buenos Aires: Fondo de Cultura Económica.

Laclau, Ernesto. 2011. Debates y combates. Por un nuevo horizonte de la política. Buenos Aires: Fondo de Cultura Económica.

Laclau, Ernesto y Chantal Mouffe. 2010. Hegemonía y Estrategia Socialista. Hacia una radicalización de la democracia. Buenos Aires: Fondo de Cultura Económica.

Miller, Jacques-Alain. 2003. "La última enseñanza de Lacan", en Lo real y el sentido, 73-106. Buenos Aires: Colección Diva.

Miller, Jacques-Alain. 2005. "Chapter One, Presentation of the Year's Theme: From Fantasy to Symptom and Return". (Re) turn 2: 11-38.

Nasio, Juan David. 1993. Cinco lecciones sobre la teoría de Jacques Lacan. Barcelona: Gedisa.

Rifflet-lemaire, Anika. 1981. Lacan. Buenos Aires: Sudamericana.

Stavrakakis, Yannis. 2010. La izquierda lacaniana. Psicoanálisis, teoría, política. Buenos Aires: Fondo de Cultura Económica.

Tonkonoff, Sergio. 2009. "Sujeción, Sujeto, Autonomía. Notas sobre una encrucijada actual”. En Ciudadanía y Autonomía, compilado por Raúl Alcalá, 135-147. México: Instituto de investigaciones filosóficas.

Zizek, Slavoj. 1998. El sublime objeto de la ideología. Buenos Aires: Siglo XXI.

Zizek, Slavoj. 1999. El acoso de las fantasías. Buenos Aires: Siglo XXI.

Zizek, Slavoj. 2004. Las metástasis del goce. Seis ensayos sobre la mujer y la causalidad. Buenos Aires: Paidós. Zizek, Slavoj. 2004b. ¡Goza tu síntoma! Jacques Lacan dentro y fuera de Hollywood. Buenos Aires: Nueva Visión. 


\begin{abstract}
Ana Belén Blanco es Licenciada en Sociología por la Universidad de Buenos Aires (UBA). Doctoranda en Ciencias Sociales (UBA). Becaria de postgrado del Consejo Nacional de Investigaciones Científicas y Tecnológicas (CONICET) de Argentina, con sede en el Instituto de Investigaciones Gino Germani (UBA). Docente de la materia "Lenguaje, deseo, cultura. Teorías sociales estructuralistas y postestructuralistas", de la carrera de Sociología de la UBA. Investigadora del proyecto UBACYT "Violencia y Cultura. La función heurística de lo abyecto" y del proyecto PIP/CONICET "La prohibición, la transgresión y el castigo. Hacia una criminología cultural", ambos proyectos dirigidos por el Dr. Sergio Tonkonoff. E-mail: blancoanabelen@hotmail.com
\end{abstract}

María Soledad Sánchez es Licenciada en Sociología por la Universidad de Buenos Aires (UBA). Doctoranda en Ciencias Sociales (UBA). Becaria de postgrado del Consejo Nacional de Investigaciones Científicas y Tecnológicas (CONICET) de Argentina, con sede en el Instituto de Investigaciones Gino Germani (UBA). Ha sido becaria CLACSO/Asdi, en la categoría Iniciación a la investigación. Docente de la materia "Lenguaje, deseo, cultura. Teorías sociales estructuralistas y postestructuralistas", de la carrera de Sociología de la UBA. Investigadora del proyecto UBACYT "Violencia y Cultura. La función heurística de lo abyecto” y del proyecto PIP/CONICET “La prohibición, la transgresión y el castigo. Hacia una criminología cultural", ambos proyectos dirigidos por el Dr. Sergio Tonkonoff. E-mail: sanchez.masoledad@gmail.com. 
